\title{
Inverse identification of tungsten static recrystallization kinetics under high thermal flux
}

\author{
A. Durif ${ }^{a, * *}$, M. Richou ${ }^{a, *}$, G. Kermouche ${ }^{b}$, J.-M. Bergheau ${ }^{c}$ \\ ${ }^{a}$ CEA, IRFM, F-13108 Saint-Paul-Lez-Durance, France \\ ${ }^{\mathrm{b}}$ École nationale supérieure des mines de Saint-Étienne, LGF, CNRS UMR 5307, 42023 Saint-Etienne cedex 2, France \\ ${ }^{\mathrm{c}}$ University of Lyon, Ecole Nationale d' ingénieurs de Saint-Etienne, LTDS, CNRS UMR 5513, 42023 Saint-Etienne, France
}

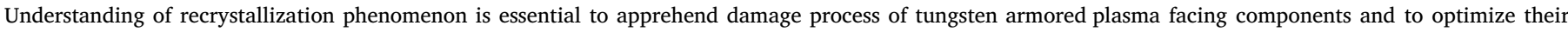

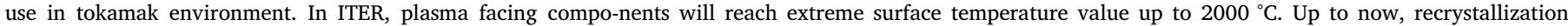

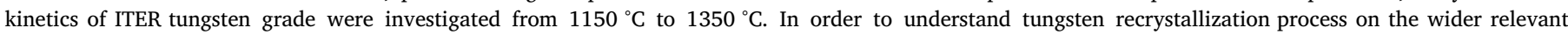

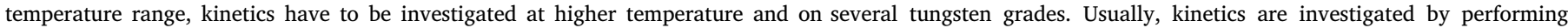

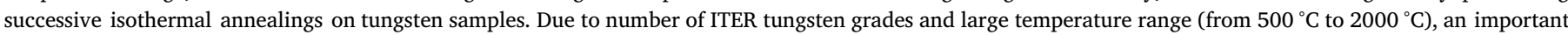

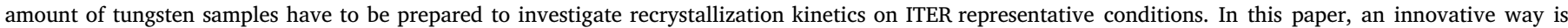

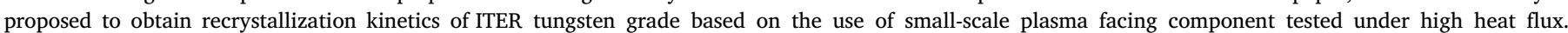

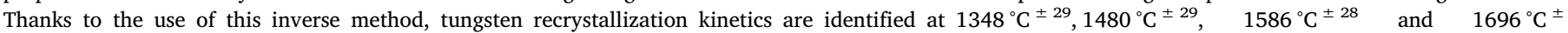

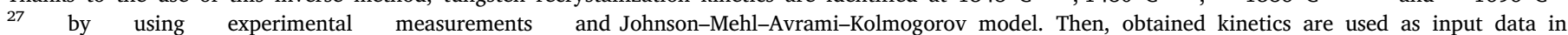
numerical post-treatments to obtain tungsten recrystallization gradients after 500 thermal cycles at $20 \mathrm{MW} / \mathrm{m}^{2}$.
\end{abstract}

\section{Introduction}

For the ITER divertor, plasma facing components are made with tungsten as armor material, bonded on a copper alloy tube as heat sink structural material and cooled by water. Such components withstand high heat flux up to $20 \mathrm{MW} / \mathrm{m}^{2}$ and consequently satisfy ITER requirements [1-6]. However, due to high heat flux, the loaded surface reaches extreme temperature values up to $2000^{\circ} \mathrm{C}$ and strong thermal temperature gradient is generated on a thickness in the range of $6 \mathrm{~mm}$ $[7,8] .2000^{\circ} \mathrm{C}$ is large enough to alter tungsten microstructure by recrystallization. Understanding of recrystallization phenomenon is essential to apprehend damage process of such components and to optimize their use in tokamak environment. Hereafter, this means tungsten recrystallization kinetics have to be investigated. Up to now, kinetics were obtained by isothermal annealings on one tungsten grade relevant with ITER specifications (called here abusively ITER tungsten grade) on a restricted temperature range from $1150{ }^{\circ} \mathrm{C}$ to $1350^{\circ} \mathrm{C}$ [9]. To fulfill the gap and then understand tungsten recrystallization phenomenon on the entire temperature range, an innovative way is proposed in this paper. Based on the use of small-scale plasma facing component tested under high heat flux, this inverse approach aims to benefit from thermal temperature gradient generated experimentally to obtain tungsten recrystallization kinetics.

In the first part of this paper, inverse methodology is described. Second, based on hardness measurements, tungsten recrystallization kinetics are identified thanks to Johnson-Mehl-Avrami-Kolmogorov model (JMAK) [10]. Then, numerical integration of obtained kinetics highlights that consistent tungsten recrystallization gradients are obtained.

\section{Assumptions}

$X=1-\exp \left(-b^{n}\left(t-t_{\text {inc }}\right)^{n}\right)$

JMAK model (equation (1)) can be used to describe the recrystallized fraction (X) evolution of material over the annealing time

\footnotetext{
*** Principal corresponding author.

* Corresponding author.

E-mail addresses: alan.durif@cea.fr (A. Durif), marianne.richou@cea.fr (M. Richou).
} 


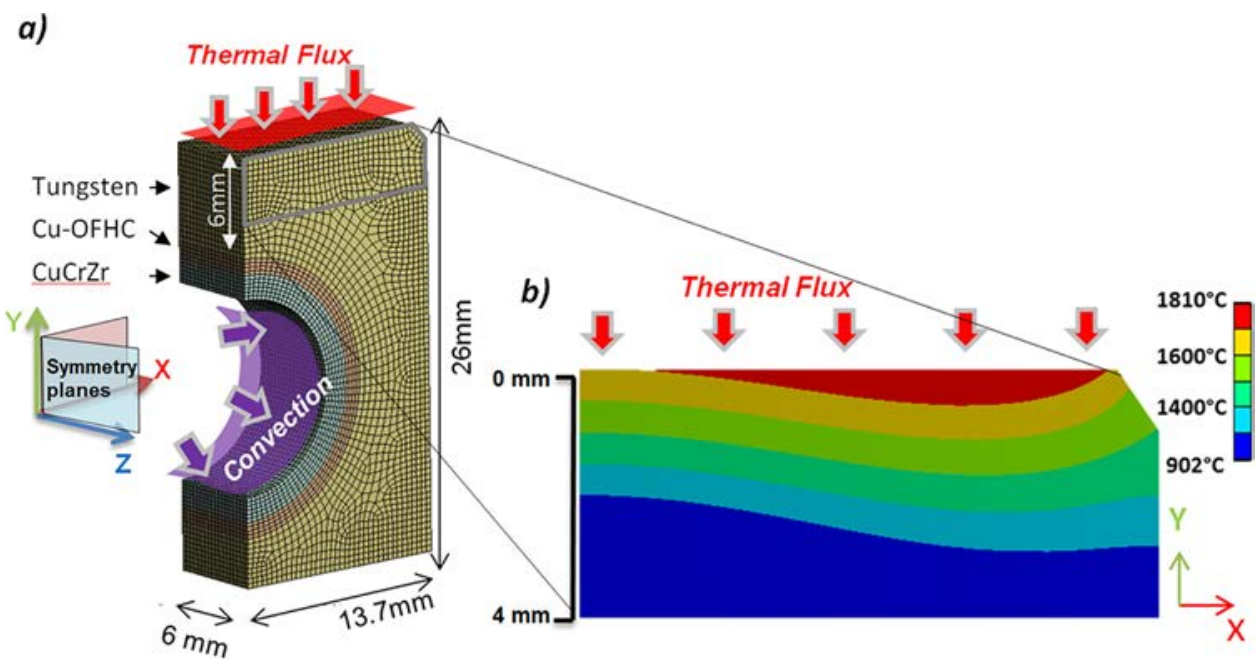

Fig. 1. a) Numerical modeling, b) Thermal temperature gradient obtained under $20 \mathrm{MW} / \mathrm{m}^{2}$.

[10]. tinc is representing the incubation time, to take into account recovery phase before recrystallization [10], $\mathrm{n}$ is the Avrami exponent set at 1.098 [9] and $b$ is thermo-dependent parameter. Recrystallization is a thermally activated process. Relationships between JMAK parameters and annealing temperature over temperature range are usually decribed by Arrhenius laws $[10,9]$. In this way, inverse approach aims to propose a method to estimate parameters $b$ and tinc at specific annealing temperatures and aim to identify Arrhenius relationships for these both parameters on a large temperature range. For that, $\mathrm{X}$ has to be estimated over different annealing times per annealing temperature.

$X=\frac{H V_{\text {in }}-H V}{H V_{\text {in }}-H V_{\text {rx }}}$

According to equation (2) $[9,11]$, X can be estimated from hardness measurements, with HV the measured hardness after any annealing time at a specific annealing temperature, $\mathrm{HV}_{r x}$ the measured hardness on fully recrystallized material and $\mathrm{HV}_{\text {in }}$ the measured hardness on initial material. Indents are performed at CEA Cadarache (IRFM) using a load of $10 \mathrm{~kg}$ and a dwell time of $10 \mathrm{~s}$ [9].

In this way, based on the use of small-scale plasma facing component tested under high heat flux, inverse approach aims to benefit from thermal temperature gradient obtained experimentally. Hardness at specific positions, corresponding to a loaded annealing temperature are performed. Annealing temperatures are identified thanks to use of the thermal temperature gradient obtained numerically. Measured hardness related to same annealing temperature per block are averaged and then converted in X (Eq. (2)).

To obtain parameters from Eq. (1), each $\mathrm{X}$ obtained is assigned to an equivalent annealing time $\left(t_{\text {annealing }}\right)$. $t_{\text {annealing }}$ per investigated block is defined as a function of number of loaded cycles $\left(\mathrm{N}_{\text {cycle }}\right)$ and steady state loaded time $(\Delta t)$ (Eq. (3)). Parameters b and tinc are then identified per investigated annealing temperature thanks to the use of least squares method regarding Eq. (1) and Arrhenius laws fitting. Finally, Arrhenius relationships are used as input data in numerical anisothermal JMAK post treatment to model tungsten recrystallization gradient after 500 thermal cycles at $20 \mathrm{MW} / \mathrm{m}^{2}$. Anisothermal JMAK model is commonly used in literature for anisothermal paths [12].

$t_{\text {annealing }}=N_{\text {cycle }} * \Delta t$

\section{Material and method}

\subsection{Materials}

In preparation of the actively cooled divertor of WEST tokamak
(PHASE 2), mock-ups were manufactured. Composed of 7 tungsten blocks supplied from Advance Technology and Materials, these were bonded on Cu-OFHC interlayer ( $1 \mathrm{~mm}$ ) finally bonded on a copper alloy tube (CuCrZr) used as heat sink structural material [13]. Tungsten block dimension is $27.4 \mathrm{~mm}$ (width) * $26 \mathrm{~mm}$ (height) * $12 \mathrm{~mm}$ (depth). The minimum distance from tungsten upper surface to the copper interlayer is $6 \mathrm{~mm}$. Tube inner diameter is $12 \mathrm{~mm}$, while the outer diameter of the tube is $15 \mathrm{~mm}$. These mock-ups were exposed to electron beam JUDITH 1 at Forschungszentrum Julich [13]. In this paper, two tungsten blocks (M4 and M5) from one mock-up named M2-2 in [13] are investigated. These were exposed to cyclic high heat flux (10s ON / 10s OFF):

-1000 cycles at $10 \mathrm{MW} / \mathrm{m}^{2}$ followed by 300 cycles at $20 \mathrm{MW} / \mathrm{m}^{2}$ for M4

-1000 cycles at $10 \mathrm{MW} / \mathrm{m}^{2}$ followed by 500 cycles at $20 \mathrm{MW} / \mathrm{m}^{2}$ for M5.

For thermal loading at $10 \mathrm{MW} / \mathrm{m}^{2}$ (in total $10 \mathrm{000s}$ ), tungsten reaches maximum temperature close to $1000{ }^{\circ} \mathrm{C}$ being not enough to have an impact on tungsten microstructure [9].

\subsection{Finite elements modeling}

Inverse approach aims to benefit from thermal temperature gradient observed under $20 \mathrm{MW} / \mathrm{m}^{2}$ to obtain tungsten recrystallization kinetics. For that, temperature gradient and equivalent annealing time over cycles is estimated using numerical simulation performed on finite elements code (ANSYS 17.2).

Numerical model presented in Fig. 1 (a), is representative to studied tungsten blocks M4 and M5. Thanks to the use of symmetry planes only quarter part of block is modeled taking into account the presence of $1 * 1$ $\mathrm{mm}^{2}$ chamfer in the modeling. 38376 quadratic elements are used to mesh the 3D geometry. Heat conductivity and coefficient of thermal expansion used are those presented for tungsten, Cu-OFHC and $\mathrm{CuCrZr}$ in [7]. In this study, $20 \mathrm{MW} / \mathrm{m}^{2}$ heat flux is applied on the upper surface and CEA routine [14] is used to calculate heat transfer coefficients $\left(\mathrm{T}^{\circ}=22{ }^{\circ} \mathrm{C}, v=10 \mathrm{~m} / \mathrm{s}\right.$ and $p=2.25 \mathrm{MPa}$ ) due to water cooling during high heat flux tests at the inner wall pipe. Fig. 1(b), highlights that thermal loadings at $20 \mathrm{MW} / \mathrm{m}^{2}$ involve strong thermal temperature gradient leading to extreme temperature values from $1810{ }^{\circ} \mathrm{C}$ at the loaded surface to $902{ }^{\circ} \mathrm{C} 4 \mathrm{~mm}$ in the depth of the block.

Maximum surface temperature obtained is compared to that measured by infrared camera during the experimental campaign [13] and revealed that numerical model estimates consistent thermal results. This map is used for the identification of positions related to specific annealing temperature. 


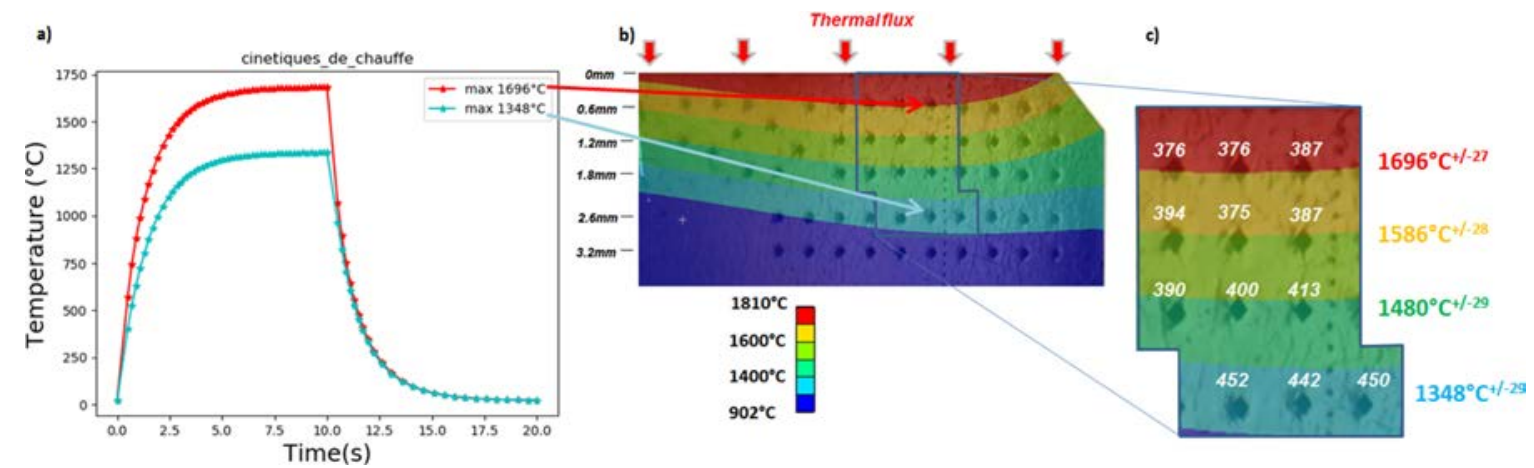

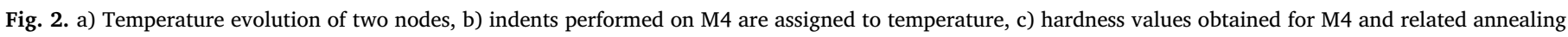
temperature.

\subsection{Annealing time}

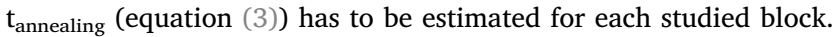
Fig. 2 (a) shows the temperature evolution (over one thermal cycle) of two nodes placed on both sides of annealing temperature range explored. Steady state is obtained after $5 \mathrm{~s}$ heating. Consequently, conservative study should be achieved assuming $\Delta t=5 \mathrm{~s}$. However, considering $\Delta t=5 \mathrm{~s}$ in this study, involves that heating phase (from $0 \mathrm{~s}$ to 5 $s$ heating) is neglected. To evaluate the impact of this assumption, kinetics will be investigated assuming two different $t_{\text {annealing }}$ per block (Table 1) with $\Delta t=5 \mathrm{~s}$ which involved shorter time to obtain fully recrystallized material (conservative study) and $\Delta t=10 \mathrm{~s}$ which assumed that entire heating phase play a role in the microstructure change.

\section{Results and discussion}

\subsection{Hardness measurements}

Fig. 2(b) shows indents performed on the external surface of block M4 and zoom Fig. 2(c) displays hardness values for each indents. Zoom highlights that hardness increases by the depth. Similar measurements are performed on block M5. Average hardness values obtained for blocks M4 and M5 are presented in Table 2. Due to a deteriorated surface of block M5, no indent is performed for positions related to annealing temperature equal to $1586{ }^{\circ} \mathrm{C}$ and $1696{ }^{\circ} \mathrm{C}$ (see Fig. 1 for global thermal gradient). Moreover, indents measure approximately $200 \mu \mathrm{m}$ diagonal which involve vertical thermal temperature gradient in the order of $50{ }^{\circ} \mathrm{C}$. Temperature assigned for each indent is consequently given with an uncertainty of $\pm 25^{\circ} \mathrm{C}$. Hardness values are then averaged over 3 indents within a same loaded temperature (Fig. 2, c). The maximum horizontal temperature variation over indents varying from $\pm 4{ }^{\circ} \mathrm{C}$ at $2.6 \mathrm{~mm}$ depth to $\pm 2{ }^{\circ} \mathrm{C}$ at $0.6 \mathrm{~mm}$ depth which involves a maximum final uncertainty of $\pm 29{ }^{\circ} \mathrm{C}$ on the average temperature estimated for each investigated zones (Fig. 2c).

To estimate $\mathrm{HV}_{\text {in }}, 20$ indents are performed on tungsten plate $\left(28 * 28 * 12 \mathrm{~mm}^{3}\right.$ ) supplied by Advance Technology and Materials (AT\& $\mathrm{M})$. Average hardness $\left(\mathrm{HV}_{\mathrm{in}}\right)$ obtained $\left(458 \mathrm{HV}_{10} \pm 2\right)$ is compared with average hardness obtained from indents performed far from the M4 loaded surface ( $451 \mathrm{HV}_{10} \pm 5$ ) revealing that material supplied can

Table 1

Equivalent annealing time assumed per block

\begin{tabular}{lll}
\hline & M4 (300 cycles) & M5 (500 cycles) \\
\hline$\Delta t=5 \mathrm{~s}$ & $1500 \mathrm{~s}$ & $2500 \mathrm{~s}$ \\
$\Delta t=10 \mathrm{~s}$ & $3000 \mathrm{~s}$ & $5000 \mathrm{~s}$ \\
\hline
\end{tabular}

Table 2

Average hardness values and related recrystallized fraction obtained

\begin{tabular}{llllll}
\hline & $\mathrm{T}\left({ }^{\circ} \mathrm{C}\right)$ & $1348^{ \pm 29}$ & $1480^{ \pm 29}$ & $1586^{ \pm 28}$ & $1696^{ \pm 27}$ \\
\hline 500 cycles & $\mathrm{Hv}_{10}$ & $425^{ \pm 8}$ & $399^{ \pm 3}$ & - & - \\
\cline { 2 - 6 }$\left(20 \mathrm{MW} / \mathrm{m}^{2}\right)$ & $\mathrm{X}(\%)$ & $41^{ \pm 10}$ & $73^{ \pm 4}$ & - & 100 \\
\hline $300 \mathrm{cycles}$ & $\mathrm{Hv}_{10}$ & $448^{ \pm 5}$ & $401^{ \pm 12}$ & $385^{ \pm 10}$ & $380^{ \pm 6}$ \\
\cline { 2 - 6 }$\left(20 \mathrm{MW} / \mathrm{m}^{2}\right)$ & $\mathrm{X}(\%)$ & $13^{ \pm 7}$ & $71^{ \pm 14}$ & $91^{ \pm 12}$ & $98^{ \pm 8}$ \\
\hline
\end{tabular}

be used to estimate $\mathrm{HV}_{\mathrm{rx}}$. Isothermal annealing at $1250{ }^{\circ} \mathrm{C}(96 \mathrm{~h})$ is achieved on tungsten sample $\left(9 * 12 * 3 \mathrm{~mm}^{3}\right)$ obtained from surface tungsten plate to estimate $\mathrm{HV}_{\mathrm{rx}}$. 20 indents are performed on the sample after annealing. Average hardness $\left(\mathrm{HV}_{\mathrm{rx}}\right)$ obtained is equal to 378 $\mathrm{HV}_{10} \pm 2$. Based on $\mathrm{HV}_{\text {in }}\left(458 \mathrm{HV}_{10} \pm 2\right)$ and $\mathrm{HV}_{\mathrm{rx}}\left(378 \mathrm{HV}_{10} \pm 2\right)$ each hardness values obtained for blocks M4 and M5 are converted in X thanks to equation (2) (Table 2).

Indents are also performed at $8.1 \mathrm{~mm}$ from the edge of block M5 in order to valid the inverse method on another part of the block. Due to thermal gradient, 5 hardness measurements are performed over the depth. Consequently, hardness is not averaged and error bars presented Fig. 4 (b) are representative to statistic obtained for $\mathrm{HV}_{\text {in }}( \pm 2)$.

\subsection{Recrystallization kinetics by inverse method}

At annealing temperatures equal to $1586{ }^{\circ} \mathrm{C}$ and $1696{ }^{\circ} \mathrm{C}$ only one $\mathrm{X}$ is provided which corresponds to measurements performed on M4. To provide another point for the determination of these kinetics, one assumption is made for the determination of $\mathrm{X}$ related to the block loaded at 500 cycles (M5). In any case, the X related to M5 for a given annealing temperature is higher than the one obtained for same annealing temperature on $\mathrm{M} 4$. At $1696{ }^{\circ} \mathrm{C}, \mathrm{X}$ is fixed at $100 \%$. Parameters b and tinc are obtained per annealing temperature by fitting equation (1) using least squares method (Table 3) for both given annealing times. Related recrystallization kinetics obtained for each annealing temperature (assuming $\Delta t=5 \mathrm{~s}$ ) and Arrhenius laws are given in Fig. 3. Arrhenius straight as the method imposes it $\left(\mathrm{R}^{2}=0.9999\right)$.

\subsection{Discussion}

Fig. 4 (a) shows tungsten recrystallization gradient obtained numerically after 500 cycles at $20 \mathrm{MW} / \mathrm{m}^{2}$ using determinated kinetics at $3.5 \mathrm{~mm}$ from the edge assuming $\Delta t=5 \mathrm{~s}$ and $\Delta t=10 \mathrm{~s}$. Average measurements obtained at $3.5 \mathrm{~mm}$ from the edge of blocks are used to fit kinetics parameters. Consequently, Fig. 4 (a) shows consistent evolution of tungsten recrystallized fraction with regard to experimental data 
Table 3

JMAK parameters identified for two annealing times using least squares method

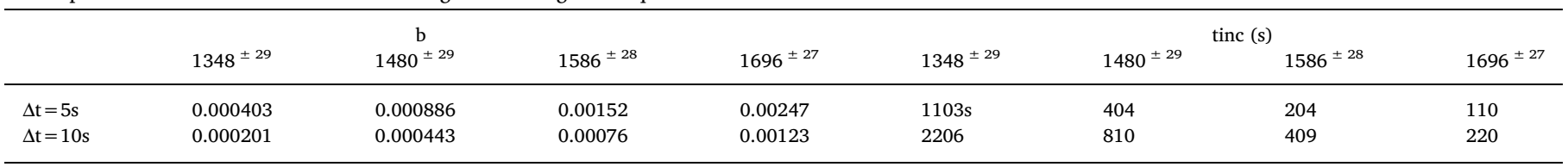
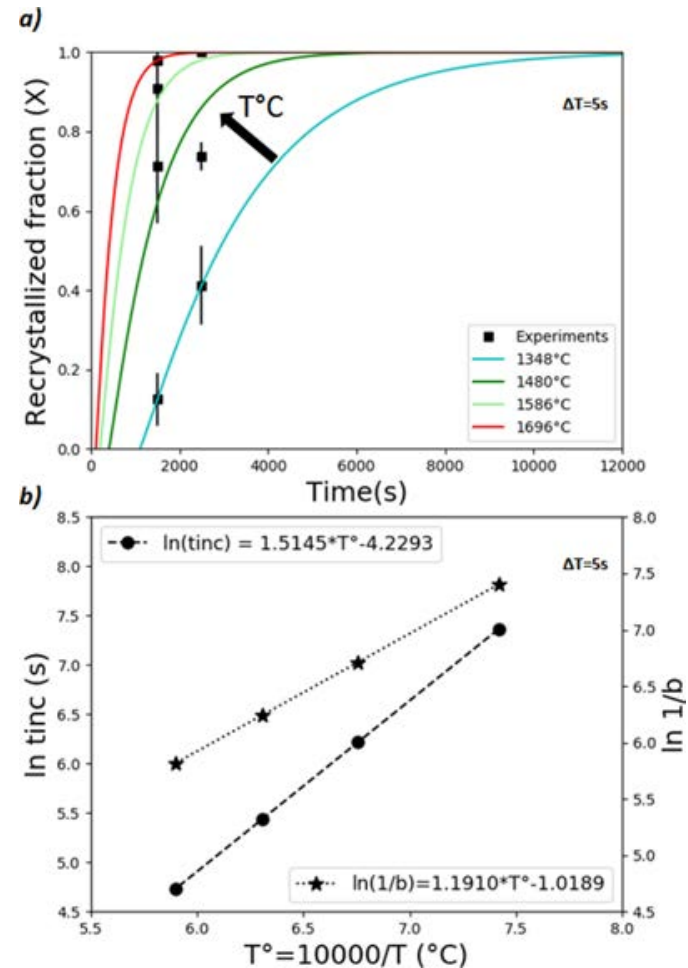

Fig. 3. a) Recrystallization kinetics obtained by inverse method and b) related Arrhenius relationships assuming $\Delta t=5 \mathrm{~s}$.

displayed Table 2. It shows also that the realistic annealing time is between $\Delta t=5 \mathrm{~s}$ and $\Delta t=10 \mathrm{~s}$.

Fig. 4 (b) highlights recrystallized fraction evolution over the block depth at $8.1 \mathrm{~mm}$ from the edge. It shows consistent predictions of $\mathrm{X}$ tendency.

In this paper, two tungsten blocks are used to fit tungsten recrystallization kinetics. In further studies, number of investigated blocks could be increased in order to optimize the fitting procedure and provide more consistent data. Also, to increase statistics and minimize temperature uncertainty per investigated kinetic, micro-indents could be considered.

\section{Conclusion}

This paper proposes an innovative way to investigate tungsten recrystallization kinetics used as armored material in plasma facing components. Here above, kinetics were obtained at $1348{ }^{\circ} \mathrm{C}^{ \pm 29}, 1480$ ${ }^{\circ} \mathrm{C}^{ \pm 29}, 1586{ }^{\circ} \mathrm{C}^{ \pm 28}$ and $1696{ }^{\circ} \mathrm{C}^{ \pm 27}$. JMAK parameters (b and tinc) obtained are extrapolated over the explored temperature range using Arrhenius relationships. To finish, these are used as input data in numerical post-treatments and consistent tungsten recrystallization gradients are obtained.

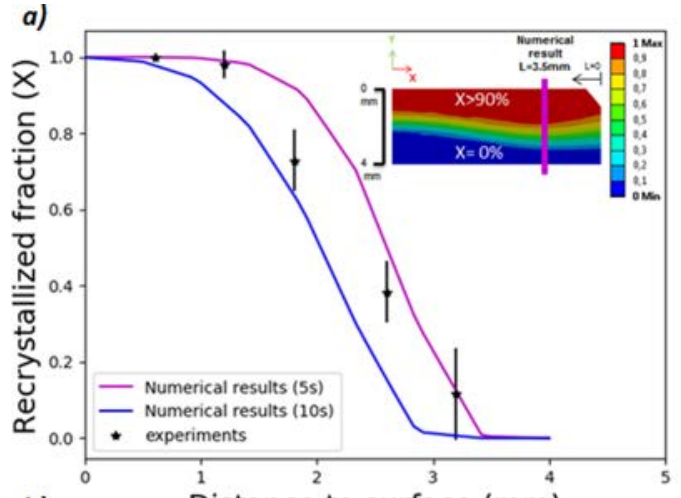

b) Distance to surface $(\mathrm{mm})$

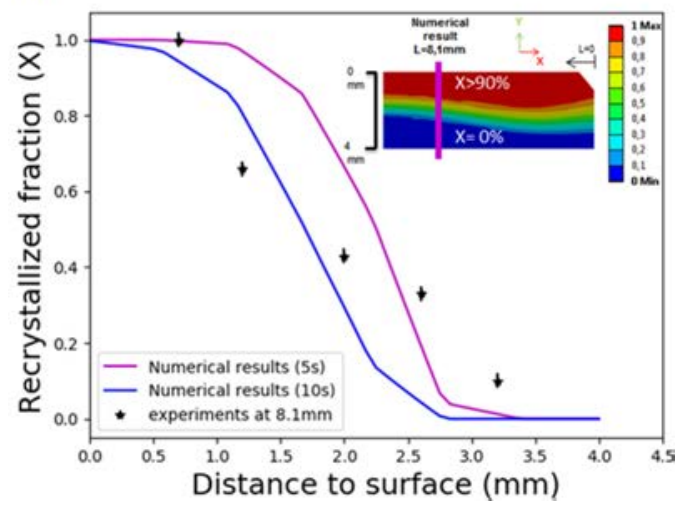

Fig. 4. Evolution of the recrystallized fraction obtained numerically for both annealing times assumed ( $5 \mathrm{~s}$ and $10 \mathrm{~s}$ ) and comparison with experiments performed at: a) $3.5 \mathrm{~mm}$ from the edge of the block, b) $8.1 \mathrm{~mm}$ from the edge of the block.

\section{Acknowledgments}

This work has received CEA funding from the "Programme Transverse de Compétence, Matériaux et Procédés (PTC-MP). This work has been carried out within the framework of the EUROfusion Consortium and has received funding from the Euratom research and training program 2014-2018 under grant agreement No 633053. The views and opinions expressed herein do not necessarily reflect those of the European Commission.

\section{References}

[1] K. Ezato, et al., Progress of ITER full tungsten divertor technology qualification in Japan, Fus. Eng. Des. 98-99 (2015 Oct) 1281-1284.

[2] G. Pintsuk, et al., Characterization of ITER tungsten qualification mock-ups exposed to high cyclic thermal loads, Fus. Eng. Des. 98-99 (2015 Oct) 1384-1388.

[3] T. Hirai, et al., Status of technology R\&D for the ITER tungsten divertor monoblock, J. Nucl. Mater. 463 (2015 Aug) 1248-1251.

[4] T. Hirai et al., Use of tungsten material for the ITER divertor, Nucl. Mater. Energy.

[5] P. Gavila, et al., High heat flux testing of mock-ups for a full tungsten ITER divertor, Fus. Eng. Des. 86 (9-11) (2011 Oct) 1652-1655.

[6] B. Riccardi, et al., Preliminary results of the experimental study of PFCs exposure to ELMs-like transient loads followed by high heat flux thermal fatigue, Fus. Eng. Des. 86 (9-11) (2011 Oct) 1665-1668. 
[7] M. Li, J.-H. You, Interpretation of the deep cracking phenomenon of tungsten monoblock targets observed in high-heat-flux fatigue tests at $20 \mathrm{MW} / \mathrm{m} 2$, Fus. Eng. Des. 101 (2015 Dec) 1-8.

[8] S. Panayotis, et al., Fracture modes of ITER tungsten divertor monoblock under stationary thermal loads, Fus. Eng. Des. 125 (2017) 256-262.

[9] A. Alfonso Lopez, W. Pantleon, D. Juul Jensen, G. Luo, Thermal stability of warmrolled tungsten, DTU Mech. Eng. (2015).

[10] F. Humphreys, M. Hatherly, Recrystallization and Related Annealing Phenomena, Second Edition, Elsevier, 2004.
[11] P. Baral, et al., In situ characterization of AA1050 recrystallization kinetics using high temperature nanoindentation testing, Mater. Design 152 (2018) 22-29.

[12] J.M. Bergheau, R. Fortunier, Finite Element Simulation of Heat Transfer, ISTEWiley, 2008 ISBN 978-1-84821-053-0.

[13] [IRFM Technical Note] P. Languille, N. Vignal, Qualification of ASIPP-AT\&M mocks-ups (W-monoblock components), CFP/NTT-2015.

[14] J. Schlosser, J. Boscary, Finite elements calculations for plasma facing components, proceedings of specialist workshop on high heat flux component cooling, Grenoble (1993). 